\title{
A leitura no ensino fundamental na perspectiva da BNCC e a relação com a biblioteca escolar
}

\author{
Reading in elementary school from the perspective of Common National Curriculum Base \\ and its relationship with the school library
}

\begin{abstract}
Angelina Quinalia Ramires
Mestranda em Ciência da Informação pela Universidade Estadual Paulista Júlio de Mesquita Filho - UNESP, Brasil.

Professor tutor virtual do Centro Universitário Eurípedes de Marília e Professora da Prefeitura Municipal de

Marília, Brasil.

E-mail: AngelinaRamires121@ @otmail.com

Mariângela Spotti Lopes Fujita

Professora Titular em Indexação pela Universidade Estadual Paulista Júlio de Mesquita Filho - UNESP, Brasil.

Docente do Programa de Pós-Graduação em Ciência da Informação da Universidade Estadual Paulista Júlio de

Mesquita Filho - UNESP, Brasil.

E-mail: mariangela.fujita@unesp.br
\end{abstract}

\section{Resumo}

A leitura reflete diretamente nos índices de aprendizagem. A prática de leitura requer compreensão além de promover o contato frequente com diferentes gêneros textuais e o contato com outras culturas, o que desenvolve atitudes de respeito pela diversidade e empatia pelo diferente. A Base Nacional Comum Curricular (BNCC) contempla a leitura como um dos quatro eixos fundamentais da linguagem. Nesse sentido, estudamos aqui a importância das bibliotecas escolares nesse contexto e exemplificamos com a situação atual das bibliotecas das escolas de ensino fundamental de Marília, SP, bem como a importância do profissional da biblioteca para que se possa desenvolver um trabalho em conjunto entre bibliotecários, professores e alunos, a fim de promover um maior nível de literacia, desenvolvendo a oralidade e maior habilidade para a escrita.

Palavras-chaves: Leitura. Biblioteca escolar. Base Nacional Comum Curricular.

\begin{abstract}
Reading directly reflects on learning indices. The practice of reading requires understanding, in addition to promoting frequent contact with different textual genres and contact with other cultures, which develops attitudes of respect for diversity and empathy for what is different. BNCC considers reading as one of the four fundamental axes of language. In this sense, we study here the importance of school libraries in this context, and we exemplify with the current situation of the libraries of elementary schools in Marília, SP, as well as the importance of the library professional so that librarians, teachers and students can work together in order to promote a higher level of literacy, developing orality and greater writing ability.
\end{abstract}

Keywords: Reading. School library. Common National Curriculum Base. 


\section{Introdução}

De acordo com o Ministério da Educação e Cultura do Brasil (BRASIL, 2016), a mente humana desenvolve funções superiores ao decifrar, compreender, generalizar, sintetizar, formular hipóteses e há pesquisas científicas realizadas internacionalmente que comprovam que a leitura faz bem ao cérebro.

Quanto mais analfabeto for o povo, mais fácil de ser manipulado pelos soberanos. É preciso mudar essa realidade e a leitura faz parte desse processo assumindo um papel muito importante.

De acordo com a $5^{\text {a }}$ edição da pesquisa Retratos da Leitura no Brasil desenvolvida pelo Instituto Pró-Livro (IPL) (INSTITUTO PRÓ-LIVRO, 2019), o brasileiro tem uma média anual de 4,96 livro por habitante entre os estudantes. No entanto, apenas 2,43 desses livros foram lidos do início ao fim. Isso deixa claro que o brasileiro ainda não considera a leitura uma prática diária. A interpretação exigida para a compreensão efetiva de um texto requer práticas de leitura e contatos frequentes com diferentes gêneros textuais. Ao ter contato com outras culturas através da leitura a criança desenvolve atitudes de respeito pela diversidade e empatia pelo diferente.

Porém, de acordo com Tokarnia (2020), que analisou dados da $5^{\text {a }}$ edição da pesquisa Retratos da Leitura no Brasil (INSTITUTO PRÓ-LIVRO, 2019), realizada pelo IPL em parceria com o Itaú Cultural, há uma série de dificuldades com relação à leitura. Entre os entrevistados, $4 \%$ disseram não saber ler, outros $19 \%$ disseram ler muito devagar; $13 \%$, não ter concentração suficiente para ler; e, $9 \%$ não compreender a maior parte do que leem.

De acordo com a pesquisa (INSTITUTO PRÓ-LIVRO, 2019), um dos fatores que influenciaram em sua leitura é o incentivo de outras pessoas. Um a cada três entrevistados, (34\%), disse que alguém os estimulou a gostar de ler.

A leitura está diretamente relacionada às bibliotecas. Ao discorrer sobre o papel da biblioteca, Queiroz (2006, p. 51) observa que no contexto educacional compete à biblioteca um importante papel derivado da sua contribuição à educação, representando tal unidade "[...] um suporte, indispensável à educação e cidadania, [...] como fonte de conhecimento e de informação insubstituível, um imprescindível depositário do saber". De acordo com o autor, a biblioteca está diretamente relacionada à educação. 
Segundo Azevedo (2019), a biblioteca escolar se encontra inserida em uma unidade escolar, nos diferentes níveis de ensino - pré-escolar, fundamental e médio -, visando atender alunos, professores e trabalhadores daquela unidade. Em alguns casos, a biblioteca estende sua ação aos familiares de alunos e à comunidade no seu entorno. Fragoso (2002) apresenta duas finalidades básicas delas, a educativa, em que reforça a ação de alunos e professores, e a cultural, em que colabora para a educação formal dos indivíduos.

Por essas razões, as bibliotecas escolares assumem um papel importantíssimo no processo de formação de leitores, pois são espaços que contemplam e promovem a aquisição do conhecimento, estão diretamente relacionadas ao conhecimento dos estudantes, seu principal objetivo é fomentar a leitura e a busca pela informação, porém, ao longo dos anos, muitas mudanças, inovações e transformações vem ocorrendo de maneira muito rápida. Em decorrência disso, as bibliotecas precisam também se transformar para se tornarem lugares prazerosos, que despertem o prazer pela leitura e que possam ir além e possam promover o acesso ao conhecimento ajudando a desenvolver competências informacionais e preparando o aluno para a vida em sociedade.

O objetivo deste estudo é investigar quais as tendências de mudanças que estão por vir e como as bibliotecas poderão se transformar para que possam ser espaços atraentes às crianças e adolescentes, capazes de despertar o interesse pela leitura. Para isso, realizamos análise da literatura sobre novas tendências das bibliotecas escolares e análise da Base Nacional Comum Curricular (BNCC) (BRASIL, 2018) para elaborar considerações a respeito das contribuições e evolução da biblioteca escolar e avaliação da proposta de ensino da leitura com mediação da biblioteca escolar para a rede municipal de ensino fundamental de Marília.

\section{O futuro das bibliotecas escolares: novas tendências}

As bibliotecas escolares estão diretamente ligadas ao conhecimento, elas exercem um papel muito importante na vida de milhares de crianças e adolescentes que veem, através delas, a oportunidade de ter contato com os mais diversos tipos de literatura, ela é uma das responsáveis pelo desenvolvimento de habilidades nos estudantes que permitam ter acesso à informação e usá-la de maneira mais efetiva.

A biblioteca escolar precisa ir além do espaço físico, ela precisa tocar o aluno de forma a propiciar uma aproximação dele com a literatura, fomentando a leitura e a busca 
Angelina Quinalia Ramires e Mariângela Spotti Lopes Fujita

pela informação. O interesse pela leitura ajuda no desenvolvimento cognitivo da criança, além disso a criança que tem contato desde cedo com a leitura é favorecida em muitos aspectos importantes para a sua formação integral, como descrito abaixo:

[...] proporciona informação e ideias fundamentais para sermos bem-sucedidos na sociedade atual, baseada na informação e no conhecimento. A biblioteca escolar desenvolve nos alunos competências para a aprendizagem ao longo da vida e estimula a imaginação, permitindo-lhes tornarem-se cidadãos responsáveis (INTERNATIONAL FEDERATION OF LIBRARY ASSOCIATION, 1999, p. 1).

Da mesma forma, de acordo com a declaração da IFLA em 2021 (INTERNATIONAL FEDERATION OF LIBRARY ASSOCIATION, 2021), as bibliotecas contribuem de maneira muito positiva para o desenvolvimento social e cognitivo do aluno, desenvolvimento esse que permite que o aluno reflita e adquira autonomia para selecionar a informação que precisa, filtrar essa informação e utilizá-la em sua vida cotidiana, de modo que ela traga mais conhecimento à sua vida:

A biblioteca escolar promove serviços de apoio à aprendizagem e livros aos
membros da comunidade escolar, oferecendo-lhes a possibilidade de se tornarem
pensadores críticos e efetivos usuários da informação, em todos os formatos e
mídias (INTERNATIONAL FEDERATION OF LIBRARY ASSOCIATION, 2021,
p. 1).

É muito importante que a leitura ultrapasse os limites do espaço escolar, permeando as ações sociais e as relações interpessoais, conforme explica o autor:

[...] o cidadão leitor mais apto, informado que é de seus direitos e também cônscio de seus deveres. Para gozar de plena cidadania e em benefício de sua própria defesa diante da sociedade, cada indivíduo deveria ser um cidadão-leitor. Pois mesmo sendo em si um ato individual, a leitura é princípio básico da convivência social. (FRAGOSO 2002, p. 124).

Fragoso (2002) explica que as mudanças no ritmo de desenvolvimento humano na terra têm crescido de maneira muito acelerada, os meios de comunicação se transformam e se aperfeiçoam muito rapidamente fazendo com que o novo se torne obsoleto a todo momento. As inovações audiovisuais parecem ameaçar o futuro dos livros convencionais.

Ascoli e Galindo (2021) afirmam que a quarta revolução é caracterizada pelo aumento significativo do volume de transformações nas diversas maneiras de produzir e acessar a informação, incentivado pelo desenvolvimento das tecnologias digitais, exige uma mudança dos serviços e produtos oferecidos pela biblioteca tradicional. Dessa forma, o bibliotecário precisa integrar esse conjunto de profissionais que farão parte dessa transformação. 
A atualização dos serviços e produtos das bibliotecas deve ser norteada pelas tendências que emergem no campo da informação. Os bibliotecários poderiam, por exemplo, explorar formas de utilizar os dados de seus usuários para melhorar experiências de descoberta de conteúdo personalizada a partir de identificação de padrões de uso (ASCOLI; GALINDO, 2021, p. 11).

De acordo ainda com Ascoli e Galindo (2021), é possível realizar atividades colaborativas com os usuários da biblioteca, através da produção de conteúdos de forma conjunta para redes sociais e plataformas de acesso aberto. Tais ações em conjunto aproximam e impulsionam um sentido de pertencimento entre o usuário e a biblioteca.

Lanzi (2013) afirma que o bibliotecário precisa ter consciência de que o mundo se encontra em constante transformação e por conta disso, deve assumir uma nova postura, a fim de que seu trabalho se mantenha fundamental e necessário nessa realidade em que a informação surge e se modifica o tempo todo.

Isso nos faz refletir sobre o futuro das bibliotecas escolares e a importância de elas se transformarem a fim de cumprir efetivamente sua função que é a de promover o acesso ao conhecimento aos usuários das mais diversas maneiras, convivendo com as novas tecnologias e fazendo delas suas grandes aliadas.

Fragoso (2002) acrescenta que, no Brasil, as bibliotecas escolares possuem um sistema arcaico de utilização e aproveitamento do acervo e, mesmo as bibliotecas que possuem recursos financeiros para modernizá-las, relutam em investir em recursos humanos, nomeando "guardiões" para as bibliotecas, que assumem a missão de realmente guardar um acervo que já é precário.

De acordo com Fragoso (2002), há poucos profissionais capacitados a exercer a função de mediadores da informação que contribuem com o processo de formação de leitores, de aprendizado e formação cultural dos alunos.

Portanto, muitos são os desafios enfrentados pelas bibliotecas atualmente a fim de que elas cumpram seus objetivos enquanto instituição, que, segundo Fragoso (2002) são, entre outros, os de:

a) cooperar com o currículo da escola no atendimento às necessidades dos alunos, dos professores e dos demais elementos da comunidade escolar;

b) estimular e orientar a comunidade escolar em suas consultas e leituras, favorecendo o desenvolvimento da capacidade de selecionar e avaliar;

c) incentivar os educandos a pensar de forma crítica, reflexiva, analítica e criadora, orientados por equipes inter-relacionadas (educadores + bibliotecários);

d) proporcionar aos leitores materiais diversos e serviços bibliotecários adequados ao seu aperfeiçoamento e desenvolvimento individual e coletivo; 
e) promover a interação educador -bibliotecário- aluno, facilitando o processo ensino-aprendizagem;

f) oferecer um mecanismo para a democratização da educação, permitindo o acesso de um maior número de crianças e jovens a materiais educativos e, através disso, dar oportunidade ao desenvolvimento de cada aluno a partir de suas atitudes individuais; g) contribuir para que o educador amplie sua percepção dos problemas educacionais, oferecendo-lhe informações que o ajudem a tomar decisões no sentido de solucionálos., tendo como ponto de partida valores éticos e cidadãos. (FRAGOS0, 2002, p. 5).

Portanto, diante desse cenário de transformação e inovação, é preciso estabelecer ações para repaginar as bibliotecas a fim de que elas possam atender às demandas de um novo usuário e competir com tantos recursos audiovisuais se destacando em meio às novas tecnologias que surgem em uma velocidade acelerada a cada dia.

Gasque e Casarin (2016) afirmam que a leitura não deixa de ser importante, porém, precisa ser ampliada para diferentes suportes e formatos e as bibliotecas precisam ser transformadas em ambientes que não contemplem apenas a apropriação da informação, elas devem contemplar a produção do conhecimento através de atividades colaborativas, conectadas e diversificadas. Dessa forma, a biblioteca escolar deve deixar para trás aquele paradigma de lugar de silêncio, onde os livros devem ser mantidos no lugar e passar a ser um espaço atrativo para o aluno.

Hough (2011) em seu estudo sobre as bibliotecas escolares na Austrália descreve algumas tendências emergentes, como o fato de o mundo estar se globalizando ao mesmo tempo em que cresce a demanda por serviços individualizados, o fato de as tecnologias agora conduzirem a mudança social (na medida em que se desenvolvem e fornecem opções antes mesmo de ser discutido se são socialmente desejáveis e aceitáveis), as tecnologias (especialmente as tecnologias baseadas na Web) estão mudando as maneiras pelas quais podemos definir a nós mesmos, nossas unidades familiares, nosso trabalho e unidades de trabalho, e nossas premissas econômicas e de "ordem social", à medida que as economias se concentram cada vez mais em "intangíveis", o conhecimento está se tornando uma mercadoria valiosa e os conceitos de valor e inovação assumem um significado mais complexo e sofisticado.

De acordo com Hough (2011), este contexto mundial de globalização fornece o amplo ambiente no qual as escolas australianas e suas bibliotecas precisam ajudar os alunos a se prepararem para o sucesso no trabalho e nos espaços sociais do século 21.

Acontece que essa realidade da Austrália não está longe da realidade em que vivemos, em um mundo globalizado, essas preocupações não são somente das escolas australianas mas 
A leitura no ensino fundamental na perspectiva da BNCC e a relação com a biblioteca escolar

das nossas também. Com certeza precisamos pensar no usuário e seu contexto, sua realidade, antes de tudo, mas, em linhas gerais, essa é uma tendência global.

Hough (2011) descreve que há evidências de que as escolas precisam evoluir para se tornar uma parte integrante das comunidades de aprendizagem em rede, contando com maiores parcerias entre as escolas, o lar e a comunidade. À medida que uma escola se adapta para enfrentar o futuro, os bibliotecários e as bibliotecas têm um papel importante a desempenhar nessa transformação.

Os bibliotecários precisam promover ativamente seu papel de "Oficial de informações" e influenciar a liderança da escola.

- As bibliotecas escolares precisam evoluir para iCentre (s), que abrigam os recursos baseados no conhecimento essenciais para a aprendizagem e a escolaridade modernas.

- O iCentre precisará fornecer aos alunos e funcionários um 'balcão único' para todos os recursos de tecnologia e necessidades de aprendizagem em uma base diária. (HOUGH, 2011, p. 4)

Estamos falando de transformações muito abrangentes que, com certeza, promovem um impacto muito grande no papel das bibliotecas escolares e dos profissionais das bibliotecas. Nesse contexto, o bibliotecário escolar deve atuar como um líder de instrução, dominando um conhecimento muito muito grande em informação, uma espécie de curador digital atuando como facilitador e-aprendizagem, colaborando também para o desenvolvimento da cidadania digital.

Gasque e Casarin, (2016) afirmam que o bibliotecário deve exercer a função pedagógica, com projetos relacionados à aprendizagem colaborativa e conectada, promovendo a integração curricular do letramento informacional.

De acordo com O'Connell, Bales e Mitchell (2015), isso requer novas habilidades e conhecimento por parte do bibliotecário como o conhecimento de licenças digitais, de dispositivos de armazenamento e gerenciamento e também se manter atualizado sobre a indústria editorial, além é claro, de dominar os aspectos relacionados ao paradigma bibliográfico tradicional.

Outro aspecto muito importante em meio a todas as transformações é o fato de que as bibliotecas escolares devem estar diretamente ligadas ao projeto pedagógico da escola, segundo Mata e Silva (2008, p. 32), essa integração é fundamental para que os recursos disponíveis sejam adequadamente direcionados às necessidades curriculares da instituição, essa aproximação entre biblioteca, professores, alunos e equipe gestora deve gerar muitos 
ganhos para o público alvo, no caso, os alunos. Trata-se de um trabalho voltado para o usuário e suas necessidades, ajudando o aluno a entender o que ele precisa buscar, contribuindo assim para o desenvolvimento do comportamento informacional do discente, de forma que ele seja capaz de refletir sobre a informação e utilizá-la em seu cotidiano de acordo com suas necessidades.

Sabemos que no mundo contemporâneo a quantidade de informações produzidas a cada dia é cada vez maior. Com a chegada de muitos recursos tecnológicos, as crianças têm possibilidade de um acesso muito fácil e rápido aos meios de comunicação em massa, entre eles, a internet. Dessa forma, tornou-se muito mais cômodo procurar a informação que se precisa em um celular do que ir até a biblioteca fazer uma pesquisa. Além disso, os meios de busca não formais são muito utilizados também, como vídeos no youtube, blogs, sites, entre outros. Porém é importante lembrar que, não basta ter uma infinidade de informações à disposição, é muito importante saber usá-las de modo a favorecer o conhecimento e a aprendizagem, ou seja, saber usá-las de acordo com a necessidade, e isso exige estratégias e ferramentas cognitivas. A facilidade de encontrar a informação não garante que essa seja a informação correta e nem a informação de que o sujeito precisa no momento. (RAMIRES; FUJITA, 2021)

De acordo com o manifesto IFLA/Unesco (INTERNATIONAL FEDERATION OF LIBRARY ASSOCIATION, 1999) está comprovado que um trabalho integrado entre professores e bibliotecários promove um maior nível de literacia na leitura e escrita, maior capacidade de resolver problemas, uso da informação e das tecnologias de informação. O benefício desse trabalho em conjunto é muito grande e só colabora para a formação integral do aluno.

Para que esse trabalho seja efetivo, é muito importante que o bibliotecário assuma o papel de mediador da informação. De acordo com Almeida Júnior (2009), a mediação é uma ação de intervenção e alteração de sentido para os sujeitos que dela participam. Esse tipo de trabalho abarca um uma proposta diferenciada, com uma pré-disposição do profissional da biblioteca em atuar de maneira ativa, envolvendo-se com a proposta do projeto, conhecendo seu público alvo, deixando de lado o velho paradigma de que as bibliotecas são lugares inacessíveis, onde não se pode fazer barulho muito menos tocar nos livros sem a previa permissão. 
A mediação da informação é um processo que se dá entre indivíduos a fim de proporcionar a transmissão e o acesso ao conhecimento, ou seja, é um processo de interação entre as pessoas.

Davallon (2007) afirma que, além da mediação proporcionar uma interação entre sujeitos ou objetos, ela implica também em uma mudança, em uma alteração da situação inicial.

Santos Neto e Almeida Júnior (2014) destacam que o papel da mediação vai além da conciliação, a mediação implica em interferências, em interlocução e está presente no processo de interpretação, de construção de sentidos e é uma ação poderosa para representar fenômenos de informação em diferentes perspectivas e contextos, desde o pessoal, profissional, institucional, social, informacional etc.

Para Santos Neto e Almeida Júnior (2014), não se pode negar a importância da interferência do profissional da informação, o mediador humano é essencial, é fundamental para o processo de mediação e não pode ser substituído pelas mídias, pelas tecnologias e pelos meios de comunicação, uma vez que, como mencionado acima, o mediador tem uma intenção, tem um propósito, é uma ação planejada, mesmo que de maneira indireta, de acordo com o usuário.

Em síntese, com as transformações do mundo contemporâneo, as bibliotecas escolares precisam ser também reestruturadas a fim de atender às demandas do usuário de maneira efetiva. Para tanto, é preciso, primeiramente que os profissionais das bibliotecas sejam capacitados para isso, tanto no sentido de serem mediadores da informação, trabalhando em conjunto com professores, alunos e alinhados ao projeto político pedagógico da escola quanto no âmbito de serem capacitados para lidar com os novos recursos tecnológicos que surgem a cada dia, pois, de nada adianta investimentos em recursos materiais se não há pessoas capacitadas para usar tais artifícios em prol do conhecimento.

A tendência é que as novas tecnologias ocupem um lugar de destaque nas bibliotecas contemporâneas, os alunos estão familiarizados com a maioria delas, porém, há a necessidade do profissional que faça essa mediação da informação, ajudando a desenvolver as competências informacionais nessas crianças e adolescentes. Tal mediação jamais será substituída por máquinas ou equipamentos, por isso a importância desse profissional bem capacitado e comprometido com a educação. 
Angelina Quinalia Ramires e Mariângela Spotti Lopes Fujita

Bibl. Esc. em R., Ribeirão Preto, v. 8, n. 1, p. 64-83, 2022. 


\section{A leitura no ensino fundamental no âmbito da Base Nacional Comum Curricular (BNCC)}

A literatura infantil contribui para o conhecimento, informação, recreação influenciando de maneira muito positiva no desenvolvimento da criança em todos os aspectos, sejam eles emocionais, sociais, cognitivos e emocionais.

O hábito e o interesse pela leitura devem ser estimulados desde muito cedo, quando a criança ainda não está alfabetizada, a leitura de forma lúdica é muito importante para isso. Ouvir histórias é algo muito prazeroso em todas as idades, principalmente para as crianças que têm sua capacidade de imaginação muito mais intensa.

O primeiro contato com a leitura é em casa com seus familiares ouvindo histórias de como ela nasceu, como escolheram seu nome, entre outros.

Garantir a riqueza da vivência narrativa desde os primeiros anos de vida da criança contribui para o desenvolvimento do seu pensamento lógico e também de sua imaginação, que, segundo Vigotsky (1992, p. 128), “a imaginação é um momento totalmente necessário, inseparável do pensamento realista."

Ao ler a criança enriquece seu vocabulário, observa o emprego de palavras então desconhecidas, assimila a grafia correta e o contexto em que são usados os novos termos. $\mathrm{O}$ resultado é a ampliação do vocabulário e o enriquecimento da escrita.

O hábito da leitura também leva à formação de cidadãos mais conscientes. Os livros convidam a criança a um mergulho em mundos e culturas diversas, levando ao respeito pela diversidade e a uma postura empática em relação ao que é diferente.

Para que a criança tenha contato com obras de literatura desde pequena ela precisa de um adulto que leia para ela ou mesmo de outra criança alfabetizada. Sabemos que nem todas as crianças têm acesso a obras literárias, elas têm um alto custo, nem sempre há bibliotecas acessíveis, por isso o professor tem uma responsabilidade muito grande de, na escola, proporcionar esse contato, estimulando o interesse pela literatura. Ao ver um adulto ler uma história a criança é influenciada a ler também.

De acordo com a Base Nacional Comum Curricular (BNCC) (BRASIL, 2018), um documento elaborado por especialistas das diversas áreas do conhecimento, de caráter normativo que define o conjunto orgânico e progressivo de aprendizagens essenciais que 
todos os alunos devem desenvolver ao longo das etapas e modalidades da Educação Básica, com o intuito de oferecer uma base para toda a educação básica brasileira, o Eixo Leitura compreende as práticas de linguagem que decorrem da interação ativa do leitor/ouvinte/espectador com os textos escritos, orais e multissemióticos e de sua interpretação, sendo exemplos as leituras para: fruição estética de textos e obras literárias; pesquisa e embasamento de trabalhos escolares e acadêmicos; realização de procedimentos; conhecimento, discussão e debate sobre temas sociais relevantes; sustentar a reivindicação de algo no contexto de atuação da vida pública; ter mais conhecimento que permita o desenvolvimento de projetos pessoais, dentre outras possibilidades.

As Diretrizes Curriculares Nacionais da Educação Infantil (BRASIL, 2013) que norteiam os rumos a serem tomados pelas escolas manifestam a importância à literatura infantil : “ as diretrizes estabelecem que se " possibilitem às crianças experiências de narrativa, apreciação e interação com a linguagem oral e escrita e o convívio com diferentes suportes e gêneros textuais orais ou escritos" Para tanto é necessário que o professor atue como leitor mostrando que a leitura pode cumprir diversas funções como informar, instruir ou divertir em diversas situações de roda de leitura, dramatizações de histórias, contações.

Conforme Rico (2021) a BNCC (divide as práticas de linguagem em quatro categorias:

- Leitura/escuta

- Escrita

- Oralidade

\section{- Análise linguística/semiótica}

Observamos que essas categorias estão interligadas entre si, o aluno que lê mais, consequentemente vai escrever e se expressar melhor, vai fazer melhor uso do vocabulário, vai cometer menos erros de ortografia e consequentemente vai saber expressar suas ideias e opiniões, tornando-se uma pessoa letrada e não apenas um decodificador de signos.

Além disso, quanto mais uma pessoa faz uso da leitura, maior o contato com culturas diferentes, o que ajuda a reduzir preconceitos.

De acordo com Rico (2021) em artigo publicado na revista Nova Escola, objetivo da Leitura/escuta (compartilhada e autônoma) é ampliar o letramento já iniciado na Educação Infantil e na família, por meio da progressiva incorporação de estratégias de leitura, 
compartilhada e autônoma, em textos de diferentes complexidades. A Base Nacional Comum Curricular considera a leitura para além do texto escrito, incluindo imagens estáticas (foto, pintura, desenho, ilustração, infográfico etc.) ou em movimento (filmes, vídeos etc.) e som (áudios e música), que circulam em meios impressos ou digitais.

A BNCC (Base Nacional Comum Curricular) propõe construir o domínio progressivo da habilidade de produzir textos em diferentes gêneros, sempre tendo em vista a interatividade e a autoria. Nos primeiros anos, isso representa saber para que serve a escrita e como ser capaz de começar a praticá-la. Para construir esse conhecimento, a indicação é levar à sala de aula situações reais de uso da língua, para que as crianças tenham bons motivos para escrever.

Segundo pesquisa do Indicador de Analfabetismo Funcional (INAF) (AÇÃO EDUCATIVA, 2018), os Analfabetos Funcionais - equivalentes, em 2018, a cerca de 3 em cada 10 brasileiros - têm muita dificuldade para fazer uso da leitura e da escrita e das operações matemáticas em situações da vida cotidiana, como reconhecer informações em um cartaz ou folheto ou ainda fazer operações aritméticas simples com valores de grandeza superior às centenas.

Para tentar mudar esse cenário preocupante e entristecedor em nosso país, é muito importante que as escolas valorizem a leitura da mesma forma de a escrita, muitos profissionais deixam a leitura para segundo plano.

O que precisamos lembrar é que, se a escrita é importante, a leitura é tão importante quanto, pois, o aluno que consegue ler e interpretar, consegue compreender não só a disciplina da Língua Portuguesa, mas também todas as outras.

É preciso interpretar as situações problemas da matemática, os gráficos e tabelas, é preciso compreender o texto de história, geografia, ciências e demais áreas do conhecimento e, por fim, é preciso ter repertório e conhecimento de estruturas textuais que só se consegue lendo, na prática.

Cabe aos profissionais da educação incentivar os alunos a ler, mas, é preciso recursos materiais para isso, de acordo com o IPL, quarenta e oito por cento dos alunos entre onze e treze anos leem livros emprestados da escola, por isso a importância de se ter uma biblioteca escolar bem estruturada e organizada, de modo que atenda às demandas dos alunos. Não se trata apenas de se ter o livro na escola, mas é preciso fazer com que esse recurso chegue até o discente. 
O objetivo da pesquisa do IPL é orientar políticas, programas e investimentos voltados para a melhoria da qualidade do atendimento das bibliotecas nas escolas públicas enquanto um ambiente informacional que promova a leitura e a pesquisa.

O Plano Nacional de Educação (BRASIL, 2014) - estabelece, como meta, a universalização das bibliotecas escolares até 2024 Projeto de Lei 9.484/18 - altera a Lei no 12.244/10, amplia o prazo de 2020 até 2024, e:

\footnotetext{
$\checkmark$ define acervo mínimo (um livro/matricula) e um bibliotecário por escola;

$\checkmark$ modifica o conceito de biblioteca nas escolas ("equipamento cultural obrigatório ao desenvolvimento do processo educativo", que terá como objetivos: disponibilizar e democratizar a informação, promover as habilidades e constituirse como espaço de recursos educativos); e,

$\checkmark$ cria o Sistema Nacional de Bibliotecas Escolares (SNBE) para: integrar todas as bibliotecas escolares à internet; estabelecer parâmetros mínimos funcionais para a instalação física e implementar uma política de acervo (gestão e atualização)

$\checkmark$ vincula parte dos recursos do Custo Aluno Qualidade inicial (CAQi) e do Custo Aluno Qualidade (CAQ) para apoio do governo federal aos estados e municípios no esforço de universalização das bibliotecas escolares até 2024.
}

De acordo com as pesquisas do Instituto Pró Livro (2019), a presença de um profissional qualificado que cuide da biblioteca e participe de atividades pedagógicas é relevante no aprendizado dos alunos.

A presença de um professor que se envolva em atividades de pesquisa e leitura e incentive os seus alunos a frequentarem a biblioteca aumenta o desempenho em Português em até 7 pontos na escala do Sistema de Avaliação da Educação Básica (SAEB), o que representa $63 \%$ de um ano de aprendizado. Também existe uma correlação alta e positiva do indicador com o Índice de Desenvolvimento da Educação Básica (IDEB), equivalente a duas vezes o que o Brasil cresceu em termos de IDEB de 2015 a 2017

Os indicadores de acervo e recursos eletrônicos também apresentam um impacto positivo no desempenho dos alunos no IDEB tanto em Língua Portuguesa quanto em Matemática.

Tendo em vista a proposta do ensino da leitura mediado pela biblioteca escolar preconizado pela BNCC, apresentamos a seguir proposta em curso na rede municipal de ensino de Marília. 


\section{O Ensino da leitura no ensino fundamental e a Biblioteca Escolar: proposta para a rede municipal de ensino de Marília}

Baughman (1993) afirma, em seu livro "Policy Making for Public Library Trustees", que, nas escolas onde há programa de biblioteca, cujas bibliotecas possuem maior acervo de livros por estudante, com um uso intenso, uma flexibilidade de horários, maior investimento de materiais, bibliotecários à disposição para atender os alunos, e coleções digitais, ajustada à estrutura curricular da escola, a nota dos alunos é mais alta.

Diante desse cenário, onde há evidências concretas de que a leitura é imprescindível para a formação integral do indivíduo, percebe-se a necessidade de que haja um trabalho interligado entre biblioteca, alunos, professores e equipe escolar, o que trará muitos benefícios ao público alvo, no caso os alunos, pois, dessa forma, o foco do trabalho será o aluno e suas necessidades, ajudando-o a entender qual sua real necessidade de busca e a desenvolver seu comportamento informacional de forma autônoma, sendo capaz de examinar a informação localizada, avaliá-la e fazer uso dela de acordo com suas necessidades.

Nas escolas Municipais de Ensino Fundamental e Infantil da Rede Municipal de Marília/SP, há uma preocupação com o eixo leitura por parte dos profissionais da educação. A Proposta Curricular do Município (MOTA; PELOSO, 2020) contempla as Competências gerais da Educação Básica, em conformidade com a BNCC, que, entre outras competências está a de

Compreender, utilizar e criar tecnologias digitais de informação e comunicação de forma crítica, significativa, reflexiva e ética nas diversas práticas sociais (incluindo as escolares) para se comunicar, acessar e disseminar informações, produzir conhecimentos, resolver problemas e exercer protagonismo e autoria na vida pessoal e coletiva.

A BNCC estabelece que:

[...] a progressão do conhecimento ocorre pela consolidação das aprendizagens anteriores e pela ampliação das práticas de linguagem e da experiência estética e intercultural das crianças, considerando tanto seus interesses e suas expectativas quanto o que ainda precisam aprender. Ampliam-se a autonomia intelectual, a compreensão de normas e os interesses pela vida social, o que lhes possibilita lidar com sistemas mais amplos, que dizem respeito às relações dos sujeitos entre si, com a natureza, com a história, com a cultura, com as tecnologias e com o ambiente. (BRASIL, 2018, p. 59)

Portanto, a leitura é capaz de desenvolver na criança todas as competências e habilidades que ela precisa para ampliar essa autonomia intercultural. A leitura se faz presente e necessária em todas as práticas educativas desenvolvidas, independente da disciplina a ser 
trabalhada, ele envolve compreensão, interpretação, promovendo uma literacia, ajudando a diminuir o índice de analfabetismo funcional tão presente no cenário de nosso país.

De acordo com a proposta Curricular do Município de Marília, (MOTA; PELOSO, 2020), a leitura faz parte das quatro práticas próprias dos diferentes usos da linguagem, conforme descrito abaixo:

\begin{abstract}
A leitura compreende as práticas que decorrem da interação ativa do leitor/ ouvinte/ espectador com textos escritos, orais e multissemióticos, visando a compreensão e interpretação dos alunos por meio da atribuição de sentido a textos diversos em situações discursivas, propiciando sua atuação autônoma, crítica e ética. (MOTA; PELOSO, 2020, p. 34)
\end{abstract}

No Município de Marília, SP há dezenove EMEFs (Escola Municipal de Ensino Fundamental, em nas escolas há o espaço físico da biblioteca e o acervo bibliográfico, porém não há profissionais da biblioteca para atuar nesses espaços. Em duas dessas escolas, foi desenvolvido um projeto chamado "Biblioteca Escolar no Ensino fundamental: em busca de um modelo alternativo", pela professora Helen Silva Castro Casarin, que incluiu formação e acompanhamento de execução de atividades dos professores junto aos estudantes e reorganização da biblioteca. De acordo com Paulo, Casarin e Manhique (2018) o intuito do projeto foi desenvolver uma biblioteca escolar que atue de forma efetiva no espaço educacional incluindo várias ações, entre elas a formação de professores.

O projeto revitalizou as bibliotecas, porém faz-se necessário a continuidade dele em todas as escolas da rede Municipal, uma vez que ele traz propostas muito relevantes que devem ser colocadas em prática tais como a formação continuada de professores no sentido de desenvolver habilidades de busca junto aos alunos, a contratação de bibliotecários, a junção do laboratório de informática com a biblioteca, além de investimento em aquisição de acervo de pesquisa, entre outros aspectos importantes que precisam ser considerados. O laboratório de informática reúne os recursos tecnológicos que se fazem necessário para contemplar as novas tendências das bibliotecas escolares com mobilização de práticas da cultura digital que também está entre as dez competências da BNCC, o que reforça a tendência de modernização das bibliotecas, através de investimentos em acervos digitais, inovações tecnológicas e recursos humanos. Dessa forma, é possível o trabalho em conjunto entre professores, alunos, bibliotecários e projetos pedagógicos a fim de que a biblioteca seja um lugar não só atraente para os alunos, mas principalmente um espaço de aquisição do conhecimento que colabore para a formação integral dos discentes. 


\section{Conclusões}

Contemplar práticas de leitura no espaço da biblioteca e promover um trabalho em conjunto com profissionais da biblioteca é muito importante para todo esse processo de letramento. Muitas vezes esse espaço não é explorado em todo o seu potencial como deveria, seja pela falta de um profissional que deveria atuar juntamente com professores e alunos, seja por falta de estrutura física adequada, seja por falta de capacitação dos professores para esse trabalho.

Portanto, há muitos aspectos a serem considerados que precisam ser colocados em prática para que o Município de Marília, assim como muitos outros, tenha uma boa estrutura de bibliotecas escolares e também um longo caminho a percorrer para que o trabalho pedagógico junto às bibliotecas seja efetivo refletindo assim em uma melhora no processo de ensino aprendizagem e na excelência do ensino público municipal.

Paralelamente à isso, é importante olhar para as ferramentas digitais e torná-las aliadas ao processo de formação do aluno e acesso ao conhecimento, acompanhando as transformações que vem acorrendo com o decorrer do tempo e se adaptando a elas, utilizando as tecnologias e os recursos modernos para aprimorar o trabalho com os usuários.

Faz-se necessário também, recursos humanos devidamente formados e alinhados à essas mudanças do mundo contemporâneo interagindo ativamente com os usuários e, no caso das bibliotecas escolares, em conformidade com proposta pedagógica da escola, trabalhando em conjunto com a equipe de educadores e alinhados com a Base Nacional Comum Curricular (BNCC) (BRASIL, 2018) que estabelece

\footnotetext{
Requerer o desenvolvimento de competências para aprender a aprender, saber lidar com a informação cada vez mais disponível, atuar com discernimento e responsabilidade nos contextos das culturas digitais, aplicar conhecimentos para resolver problemas, ter autonomia para tomar decisões, ser proativo para identificar os dados de uma situação e buscar soluções, conviver e aprender com as diferenças e as diversidades (BRASIL, 2018).
}

Tudo isso ao encontro com as novas tendências das bibliotecas, onde se faz necessário desenvolver um trabalho mais dinâmico, pensando na formação integral do indivíduo a fim de se construir uma sociedade mais justa, democrática e inclusiva, pois, de acordo com Brasil (2018), o estímulo ao pensamento criativo, lógico e crítico, através da construção e do fortalecimento da capacidade de fazer perguntas e de avaliar respostas, de argumentar, de interagir com diversas produções culturais, de fazer uso de tecnologias de informação e 
Angelina Quinalia Ramires e Mariângela Spotti Lopes Fujita

comunicação, garante os alunos a capacidade de ampliar sua compreensão de si mesmos, do mundo natural e social, das relações dos seres humanos entre si e com a natureza.

\section{Referências}

AÇÃO EDUCATIVA. INSTITUTO PAULO MONTENEGRO. INAF Brasil 2018: resultados preliminares. São Paulo: Ação Educativa; IPM, 2018. 22p. Disponível em: https://acaoeducativa.org.br/wp-content/uploads/2018/08/Inaf2018_Relat\%C3\%B3rioResultados-Preliminares_v08Ago2018.pdf. Acesso em: 25 jun. 2021.

ALMEIDA JÚNIOR, O. F. Mediação da informação e múltiplas linguagens. Pesquisa Brasileira em Ciência da Informação, Brasília, v. 2, n. 1, p. 89-103, 2009. Disponível em: http://revistas.ancib.org/index.php/tpbci/article/view/170. Acesso em: 04 maio 2021.

ASCOLI, A.; GALINDO, M. L. A quarta revolução e a necessária reinvenção da biblioteconomia. Encontros Bibli: Revista Eletrônica de Biblioteconomia e Ciência da Informação, Florianópolis, v. 26, p. 1-21, 2021. DOI: 10.5007/1518-2924.2021.e75961. Acesso em: 10 set. 2021.

Ramires, Angelina Quinalia; Fujita, Mariângela Spotti Lopes. A mediação da informação para alunos dos anos iniciais pelo professor. In: ENCONTRO DE PESQUISA INFORMAÇÃO E MEDIAÇÃO, 3., 2021, Marília. Anais... Marília: UNESP, 2021. Disponível em: http://portalconferenciasppgci.marilia.unesp.br/index.php/IIIEPIM/IIIEPIM/schedConf/progra m. Acesso em: 25 jun. 2021.

AZEVEDO, A. L. Bibliotecas: função esperada e retrato real. Revista ACB: Biblioteconomia em Santa Catarina, Florianópolis, v. 24, n. 1, p. 62-71, 2019. Disponível em: http://hdl.handle.net/20.500.11959/brapci/112540. Acesso em: 11 set. 2021.

BAUGHMAN, J. C. Policy making for public library trustees. Englewood: Libraries Unlimited, 1993. 110p.

BRASIL. Ministério da Educação. Base nacional comum curricular: educação é a base. Brasília: Ministério da Educação, 2018. Disponível em: http://basenacionalcomum.mec.gov.br/images/BNCC_EI_EF_110518_versaofinal_site.pdf. Acesso em: 03 maio 2021.

BRASIL. Ministério da Educação. Plano nacional da educação. Brasília: Ministério da Educação, 2014. Disponível em: http://pne.mec.gov.br/. Acesso em: 24 jun. 2021.

BRASIL. Ministério da Educação. Diretrizes curriculares nacionais. Brasília: MEC, SEB, DICEI, 2013. Disponível em:

http://portal.mec.gov.br/index.php?option=com_docman\&view=download\&alias=13448diretrizes-curiculares-nacionais-2013-pdf\&Itemid=30192. Acesso em: 03 maio 2021.

BRASIL Ministério da Educação e Cultura. Assessoria de Comunicação Social. Pesquisas científicas comprovam que o hábito de ler promove o desenvolvimento do cérebro. Brasília: MEC, 2016. Disponível em: http://portal.mec.gov.br/ultimas-noticias/211- 
218175739/40291-estudos-comprovam-que-o-habito-de-ler-traz-beneficios-ao-cerebro. Acesso em: 25 jun. 2021.

DAVAllON, J. A mediação: a comunicação em processo? Prisma.com, Porto, n. 4, 2007. Disponível em: https://ojs.letras.up.pt/index.php/prismacom/article/view/2100. Acesso em: 22 mar. 2021.

FRAGOSO, G. M. Biblioteca na escola. Revista ABC: Biblioteconomia, Santa Catarina, Florianópolis, v. 7, n. 1, p.124-131, 2002. Disponível em:

https://revista.acbsc.org.br/racb/article/view/380/460. Acesso em: 22 jun. 2021.

GASQUE, K. C. G. D.; CASARIN, H. C. S. Bibliotecas escolares: tendências globais. Em Questão, Porto Alegre, v. 22, n. 3, p. 36-55, set./dez. 2016. DOI:

http://dx.doi.org/10.19132/1808-5245223.36-55. Acesso em: 25 jun. 2021.

HOUGH, M. Libraries as iCentres: helping schools. Australian School Library Association, Melbourne, v. 25, n. 1, p. 5-9, 2011. Disponível em:

http://www.asla.org.au/publications/access/access-commentaries/icentres.aspx. Acesso em: 22 de set. 2021

INSTITUTO PRÓ-LIVRO. Relatos da leitura em bibliotecas escolares. São Paulo: Instituto Pró-Livro, 2019. Disponível em: https://www.prolivro.org.br/5a-edicao-de-retratos-da-leiturano-brasil-2/a-pesquisa-5a-edicao. Acesso em: 25 jun. 2021.

INTERNATIONAL FEDERATION OF LIBRARY ASSOCIATION. Manifesto

IFLA/Unesco para biblioteca escolar. 1999. Disponível em:

https://www.ifla.org/files/assets/school-libraries-resource-centers/publications/school-librarymanifesto-pt-brazil.pdf. Acesso em: 22 mar. 2021.

INTERNATIONAL FEDERATION OF LIBRARY ASSOCIATION. IFLA/UNESCO school library manifesto. 2021. Disponível em: https://www.ifla.org/node/93585?og=52. Acesso em: 21 jun. 2021.

LANZI, Lucirene Andréa Catini; FERNEDA, Edberto; VIDOTTI, Silvana Aparecida Borsetti Gregorio. A biblioteca escolar e a geração nativos digitais: construindo novas relações. São Paulo: Cultura Acadêmica, 2013. (Coleção PROPG Digital - UNESP). Disponível em: http://hdl.handle.net/11449/109286. Acesso em: 14 jun. 2021.

MATA, M. L.; SILVA, H. C. Biblioteca escolar e aplicação da proposta da competência em informação no ensino fundamental. Revista CRB-8 Digital, São Paulo, v. 1, p. 28-39, 2008.

MOTA, D. R. N; PELOSO, R. C. B. (Org.). Proposta curricular: ensino Fundamental - $1^{\circ}$ ao $5^{\circ}$ ano do Sistema Municipal de Ensino de Marília. Marília: Secretaria Municipal da Educação, 2020. 662p.

O'CONNELL, J.; BALES, J.; MITCHELL, P. [R]Evolution in read-ing cultures: 2020 vision for school libraries. The Australian Library Journal, [S. l.], v. 64, n. 3, p. 194-208, 2015. DOI: $\underline{10.1080 / 00049670.2015 .1048043}$. Acesso em: 18 junho 2021

PAULO, R. B.; CASARIN, H. C. S.; MANHIQUE, I. L. E. Competência em informação e biblioteca escolar no ensino fundamental. In: ENCONTRO NACIONAL DE PESQUISA EM 
Angelina Quinalia Ramires e Mariângela Spotti Lopes Fujita

CIÊNCIA DA INFORMAÇÃO, 19., 2018, Marília. GT3. Marília: UNES`P, 2018. Disponível em: http://hdl.handle.net/20.500.11959/brapci/102702. Acesso em: 25 jun. 2021.

QUEIROZ, A. M. C. A biblioteca, uma organização sociocultural e instrumento a serviço da educação e cidadania. 2006. 53f. Monografia (Especialização em Metodologia da Educação Superior) - Faculdade Batista Brasileira, Salvador, 2006.

RICO, R. Como trabalhar as quatro práticas previstas na base. NOVA ESCOLA, 2021. [Associação Nova Escola; Fundação Leman, 2021]. Disponível em https://novaescola.org.br/bncc/conteudo/42/como-trabalhar-as-quatro-praticas-de-linguagemprevistas-na-base. Acesso em: 25 jun. 2021.

SANTOS NETO, J. A.; ALMEIDA JUNIOR, O. F. O conceito de mediação implícita da informação no discurso dos bibliotecários. In: ENCONTRO NACIONAL DE PESQUISA EM PÓS-GRADUAÇÃO EM CIÊNCIA DA INFORMAÇÃO (ENANCIB), 15., 2014, Belo Horizonte. Anais... Belo Horizonte: ANCIB: PPGCI/ECI/UFMG, 2014. p. 1241-1257.

TOKARNIA, M. Brasil perde 4,6 milhões de leitores em 4 anos. Agencia Brasil, 11 de novembro de 2020. Disponível em: https://agenciabrasil.ebc.com.br/educacao/noticia/202009/brasil-perde-46-milhoes-de-leitores-em-quatro-anos. Acesso em: 25 jun. 2021.

VYGOTSKY, Lev. S. A formação social da mente: o desenvolvimento dos processos psicológicos superiores. 4 ed. São Paulo: Martins Fontes, 1992 